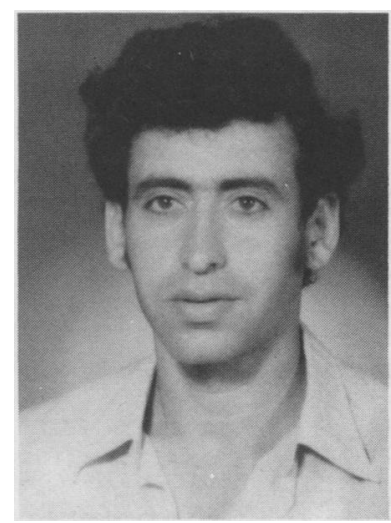

A. Israeli

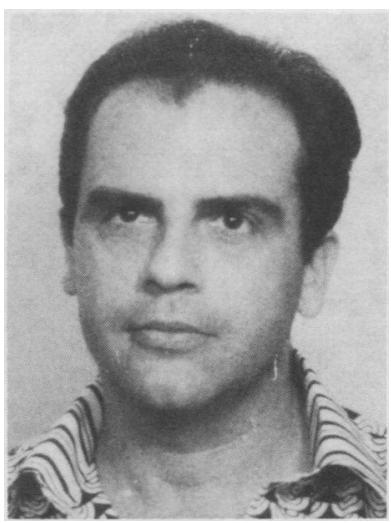

A. Ganel

\title{
CHEMONUCLEOLYSIS IN THE TREATMENT OF LUMBAR DISC DISEASE
}

\author{
A. ISRAELI, MD, A. GANEL, MD, H. HOROSZOWSKI, MD and I. FARINE, MD
}

\section{Department of Orthopaedic Surgery A, Chaim Sheba Medical Center, Tel-Aviv University, Sackler School of Medicine, Tel Hashomer, Israel}

\section{INTRODUCTION}

Low back pain is a common disability affecting almost $80 \%$ of the population once in their active lifetime. Most of the patients recover with or without the various modalities of conservative treatment (Nachemson, 1976). However, those who do not are candidates for surgical intervention, whereby excision of a herniated intervertebral disc is most frequently performed (Spengler and Freeman, 1979).

This approach is recently challenged by an alternative procedure, chemonucleolysis which is believed to reduce the incapacity associated with the symptomatic intervertebral disc disease (Nordby, 1983).

This article presents two typical cases of active sportsmen treated by chemonucleolysis. The indications, technical details and results of this still controversial method are discussed.

\section{ILLUSTRATIVE CASE HISTORIES}

\section{Case 1}

A 36-year-old woman amateur tennis player had suffered intermittent attacks of back pain and right sciatica for some years. The last attack persisted for 3 months and resulted in complete sport incapacity. The pain was located mainly in the right buttock, lateral thigh and leg. It was not relieved by various modalities of conservative treatment including bed rest and intensive anti-inflammatory drug therapy for two weeks. Physical findings were a list to the left and loss of lumbar lordosis, straight leg raising was limited to $30^{\circ}$ on the right and $60^{\circ}$ on the left, hypo-aesthesia on the lateral aspect of the leg and medial aspect of the right, foot, weakness of extension of the big toe and ankle, the knee and ankle jerks were normal. Roentgenograms demonstrated slight narrowing of the L4L5 disc space. Computed tomography showed clearly a disc herniation at that level (Fig. 1). Under general endotracheal anaesthesia chemonucleolysis was performed. Four thousand units of chymopapain were injected into the centre of the damaged L4-5 disc. Twenty-four hours following the injection

\section{Correspondence to:}

A. Israeli, MD

Department of Orthopaedic Surgery A,

The Chaim Sheba Medical Center.

Tel Hashomer, 52621, Israel

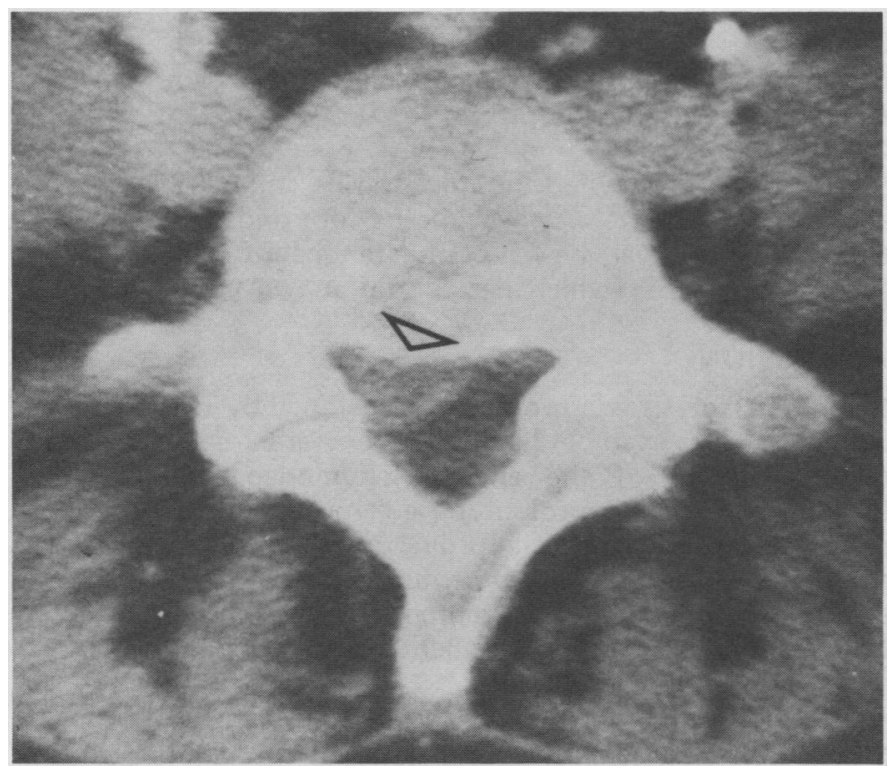

Fig. 1: C.T scan of the Ly-5 disc space. A large right herniated nuceus pulposus is demonstrated. The soft tissue density of the herniated disc (black arrow) is obliterating much of the epidural fat and is compressing the right anterior portion of the thecal sac.

the patient reported that her sharp leg pain disappeared completely. She had a slight dull ache in her right leg and some back stiffness and soreness which lasted for three weeks. One month after the injection complete neurological recovery was detected and she gradually resumed full sport activity.

\section{Case 2}

A 17-year-old basketball player had an acute attack of back pain and left sciatica. Despite intensive conservative treatment he could not resume sport activity for almost 3 months. On admission the positive physical findings were; loss of lumbar lordosis, straight leg raising limited to $20^{\circ}$, hypo-aesthesia on the lateral aspect of the leg and foot, and diminished Achilles reflex on the left side. Disc herniation at L5-S1 level was demonstrated on water soluble myelography (Fig. 2).

At this stage, chemonucleolysis was elected as the last step in the conservative treatment. Four thousand units of chymopapain were injected into the L5-S1 disc. Three days later he 


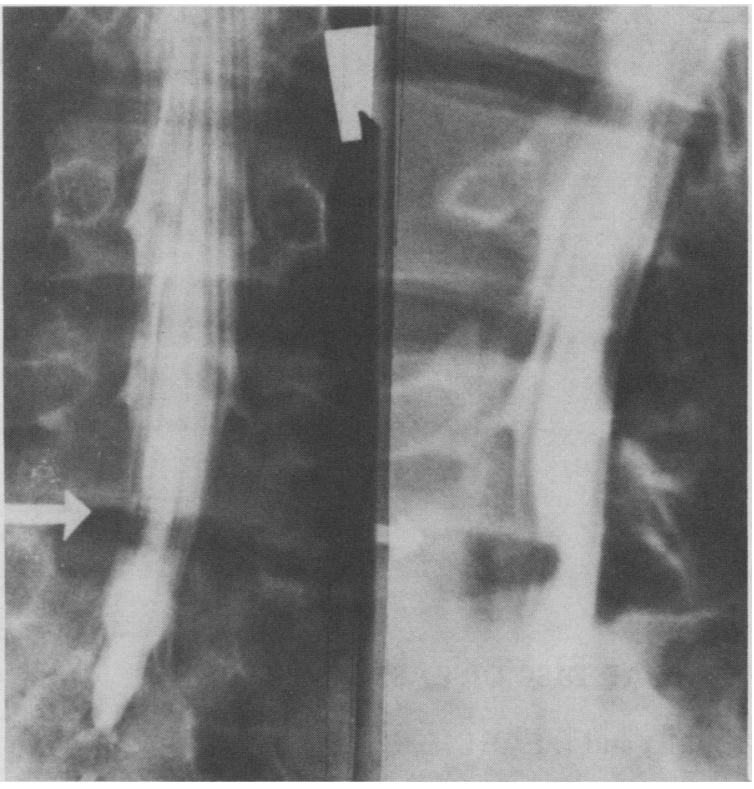

Fig. 2: Metrizamide myelography of Case 2. AP and oblique views demonstrate left-sided herniation of the L5-S, intervertebral disc (arrow).

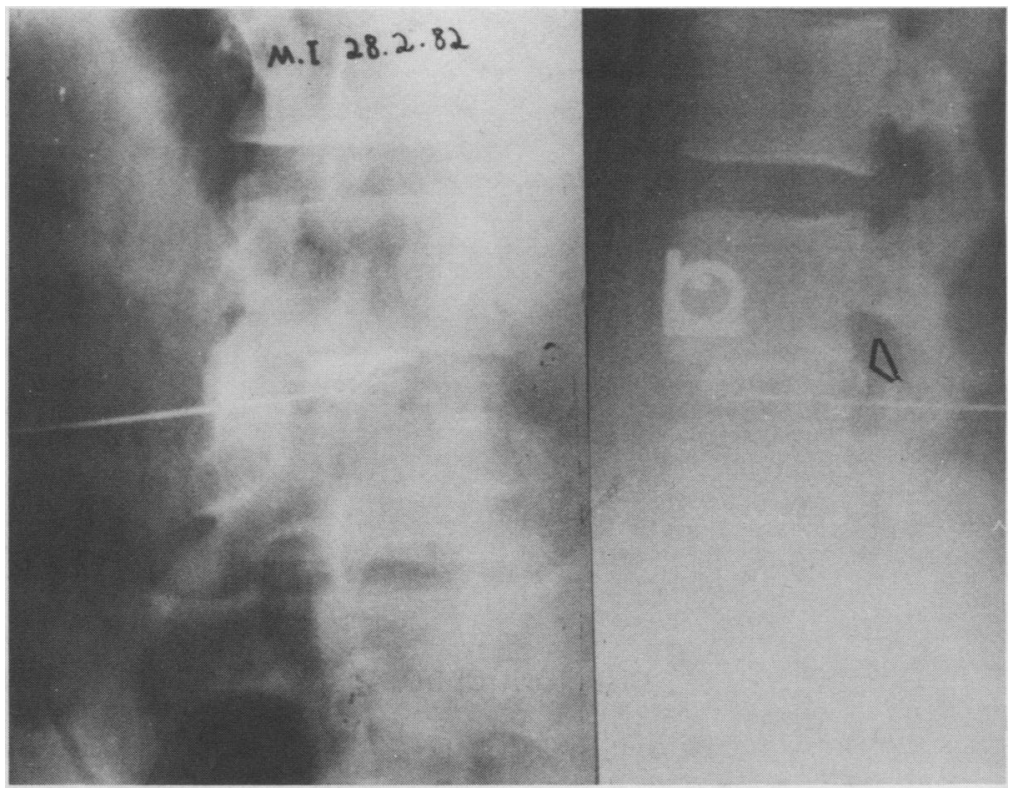

Fig. 3: X-Ray photograph of the needle in the correct position, its tip in the centre of the L4-5 disc space. The posterior bulge of the herniated disc is seen clearly. had a marked relief of his leg pain. Slight back pain was noted and straight leg raising improved to $70^{\circ}$.

One month following the injection he still had slight hypoaesthesia on the lateral aspect of the foot and diminished left ankle jerk. However, he was completely pain free and resumed full sports activity which he still did at two years follow-up.

\section{DISCUSSION}

Chemonucleolysis is a procedure, developed by Lyman Smith, whereby intervertebral disc herniations are treated by intradiscal injection of the enzyme chymopapain (Smith and Brown, 1967). This proteolytic enzyme is derived from the papaya plant, whose special properties were recognised by the ancient Polynesians. Many centuries before its therapeutic application, they used to wrap cuts of meat in papaya leaves to make them tender and succulent (Macnab, 1973).

Chymopapain has a specific proteolytic activity. It degrades primarily the mucopolysaccharides while very little or no collagen is dissolved. Thus the mucopolysaccharides-rich nucleus pulposus disintegrates while the collagen-rich annulus fibrosus is spared (Stern and Smith, 1967). This lessens the intradiscal osmotic activity, decreases its water binding capacity and reduces the intradiscal pressure. Thereby the bulging disc regresses and the compressed tensed and irritated nerve root is relieved (McCulloch, 1980; Smith and Brown, 1976).

This attractive mechanism resolves only nerve root symptoms produced by a herniated intervertebral disc. Other causes of low back pain and sciatica are not amenable to chymopapain injection (Wiltse, 1983).

Disc herniation has a well established clinical presentation. It is claimed to be associated with five cardinal criteria composed of 2 symptoms, 2 signs and one investigative procedure (McCulloch, 1977). These are: (1) Unilateral leg pain in a typical sciatic or femoral root distribution. It is the dominant symptom when compared with the back pain. (2) Specific symptoms incriminating a single nerve root such as paraesthesia localised to a dermatomal distribution. (3) Straight leg raising limited by at least $50 \%$ of normal. (4) Two of four neurological changes; wasting, motor weakness, sensory alteration and reflex changes. (5) Positive roentgenographic study showing a disc herniation at the suspected clinical level. A patient with three or more of these criteria most probably has a herniated intervertebral disc as the cause of his symptoms (McCulloch, 1977). As most of these patients recover spontaneously (Nachemson, 1976), a reasonable period of conservative treatment should be attempted before chemonucleolysis is considered. This is either three months of ambulatory care or 2 weeks of complete bed rest without improvement (McCulloch, 1977). These indications are very similar to those for operative treatment. ${ }^{*}$ Thus the ideal candidate for chemonucleolysis is the ideal one for disc excision and no short cuts should be taken (Wiltse, 1983). The contraindications are as follows (Wiltse, 1983).

a) Absolute -

(1) Allergy to papaya or enzyme meat tenderisers.

(2) Rapidly developing severe neurological deficit. b) Relative -

(1) Spinal stenosis, (2) Pregnancy, (3) Arachnoiditis and

(4) Prior injection of chymopapain.

The procedure may be performed either under general or local anaesthesia.

Under fluroscopic control a needle is passed into the damaged disc, using a posterolateral approach. Discography is performed to verify the position of the needle and 4,000 units of chymopapain are injected into the centre of the disc, as shown in Fig. 3.

Following the injection immediate relief of sciatica is usually noted while back pain may be aggravated and persist for several weeks. The patients are allowed to get up using a soft elastic corset as soon as they wish usually 12 to 48 hours after the procedure. Light activities are resumed within one to six weeks while heavier ones are allowed after about three months (Wiltse, 1983; Nordby, 1983). The frequency of complication is low compared with the alternative surgical intervention. The one to be concerned about is anaphylaxis which occurs in $0.2 \%$ of the patients (Watts, 1977). This can usually be controlled when adequate cardiovascular resuscita-

* Many rheumatologists and orthopaedic surgeons and physicians in Britain are reluctant to offer this injection to patients who are not prepared to accept surgery if the chymopapain is ineffective - Editor. 
tion measures are available. Therefore appropriate precautions are mandatory (Wiltse, 1983; McCulloch, 1977).

Success of chemonucleolysis is relief of symptoms and resumption of full activity. This is achieved in about $70 \%$ of the properly selected patients (Nordby, 1983; Wiltse, 1983; McCulloch, 1980) with a lasting effect for up to 13 years (Nordby, 1983). Thus this "semi-invasive" procedure makes surgery unnecessary for a substantial number of patients. Failure does not prejudice the results of open discectomy when necessary (Wiltse, 1983). As opposed to surgery it is not associated with muscular ligamentous or bony interven tion. Those even when limited may interfere with restoration of maximal performance of an active sportsman. Therefore chemonucleolysis should be considered as the last resort in the conservative treatment of the symptomatic herniated disc. When properly used it reduces the morbidity and incapacity associated with this common disease.

\section{References}

McCulloch, J. A., 1977 "Chemonucleolysis". J.Bone Joint Surg. 59B: 45-52.

McCulloch, J. A. 1980 "Chemonucleolysis: Experience with 2,000 cases". Clin.Orthop.Rel.Res. 146: 128-135.

Macnab, I., 1973 "Chemonucleolysis". Clin.Neurosurg. 20: 183-192. Nachemson, A. L., 1976 "The lumbar spine: an orthopaedic challenge". Spine 1: $59-71$.

Nordby, E. J., 1983 "Chymopapain in intradiscal therapy". J.Bone Joint Surg. 65A: 1350-1353.

Smith, L. and Brown, J. E., 1976 "Treatment of lumbar intervertebral disc lesions by direct injection of chymopapain". J.Bone Joint Surg. 49B: 502-519.

Spengler, D. M. and Freeman, C. Q., 1979 "Patients selection for lumbar discectomy. An objective approach". Spine 4: 129-135.

Stern, I. J. and Smith, L., 1967 "Dissolution by chymopapain in vitro of tissue from normal and prolapsed intervertebral discs". Clin. Orthop.Rel.Res. 50: 269-277.

Watts, C., 1977 "Complications of chemonucleolysis for lumbar disc disease". Neurosurg. 1: 2-5.

Wiltse, L. L. 1983 "Chemonucleolysis in the treatment of lumbar disc disease". Orthop.Clin.N.A. 14: 605-622.

\section{OBITUARY}

\section{Professor Gordon Ferguson, MRCVS, TD}

Gordon Ferguson's sudden death on 4th October, 1984 came as a shock to his many friends and colleagues. Gordon was born on 28th September, 1920 and after attending Blackburn and Manchester Grammar Schools entered the University of Edinburgh and the Royal (Dick) Veterinary College, Edinburgh. He qualified as a Member of the Royal College of Veterinary Surgeons and graduated BSc in July 1944. He immediately joined the Royal Army Veterinary Corps and was soon sent to India, where among his appointments, he was Garrison Veterinary Officer, Ahmednagar. He also served in Egypt.

After the war he returned to the United Kingdom to command the Veterinary Hospital at Melton Mowbray. Gordon would happily have made his career in the RAVC but for family reasons he returned to civilian life in 1947 and to the Royal (Dick) Veterinary College where he obtained the Diploma in Veterinary State Medicine in 1948. He then joined the Department of Veterinary Hygiene of the "Dick" as a junior lecturer becoming a senior lecturer 2 years later. After the "Dick" became part of Edinburgh University, the Department was renamed the Department of Animal Health. He became its Acting Head in 1971 and William Dick Professor of Animal Health in 1973. Throughout his career he gave a lead in veterinary public health especially where an interdisciplinary approach could succeed. Throughout the 1960s and 1970s those of us involved in Sports Medicine in Scotland appreciated Gordon's quiet courteous diligent involvement through his commitment to the British Horse Society. He joined the BASM in 1965.

All equine matters greatly interested him and he was responsible for Bush Home Farm Stables which are a valued resource for teaching equine management and equitation, not only to veterinary students, but to other undergraduates and members of the University Staff.

He was involved in horse riding for spastics and disabled children and in the Scottish Trekking and Riding Association as well as being an official of the British Horse Society. He became a member of the Council of the British Equine Veterinary Association in 1960 and its President in 1971. As a member of the Worshipful Company of Farriers he was a Freeman of the City of London.

Despite this academic and professional activity, Gordon Ferguson retained his enthusiasm for military matters and he served in the regular army reserve of officers from 1947 to 1958. After an interval in the Civil Defence Corps, he joined the Territorial Army in 1963 and was staff captain, squadron officer and then second-in-command of the Edinburgh and Heriot-Watt Universities' Officers Training Corps until his retirement from the Territorial Army in 1975. For part of this time he served with the Royal Corps of Transport, a reflection of his 'hands-on' approach to mechanical matters and his pleasure in cars and vehicles of all sorts. He was especially well suited for responsibility in the OTC because of his interest in the personal development of students. When he retired from the Territorial Army he became Commandant of the Lothian Battalion of the Army Cadet Force, an appointment he still held at the time of his death. He continued, also until then, to respresent the two Universities at the Council of Military Education Committees of the Universities of the United Kingdom.

The extent of his activities would have daunted many a younger man yet, since 1976, when he was badly injured in a road accident, he had also borne physical disability and almost constant pain with great fortitude and determination.

Colonel Gordon Ferguson, TD, committed himself to the service of others. He strove for perfection and he set high standards for himself and for those he served. His quiet firmness of purpose was blended with courtesy and moderated by his understanding of both people and animals.

Our sincere sympathy is extended to his wife Jean, and daughter, Sheila, in their sad loss. 